$$
\text { Pontifícia Universidade C Católica }
$$

Paula Gonçalves Barbosa

Profissão de Ourives: descobrindo valores e motivações de diferentes gerações de profissionais

Dissertação de Mestrado

Dissertação apresentada ao Programa de Pós-Graduação em Administração de Empresas da PUC-Rio como requisito parcial para obtenção do título de Mestre em Administração de Empresas.

Orientadora: Profa. Ana Heloisa da Costa Lemos

Rio de Janeiro

Abril de 2011 


$$
\begin{gathered}
\text { Pontifícia Universidade } \\
\text { Do Rio de Janelro }
\end{gathered} \text { Cólica }
$$

Paula Gonçalves Barbosa

\title{
Profissão de Ourives: descobrindo valores e motivações de diferentes gerações de profissionais
}

Dissertação apresentada como requisito parcial para obtenção do título de Mestre pelo Programa de PósGraduação em Administração de Empresas da PUC-Rio. Aprovada pela Comissão Examinadora abaixo assinada.

\author{
Prof $^{\mathrm{a}}$. Ana Heloisa da Costa Lemos \\ Orientadora \\ Departamento de Administração - PUC-Rio
}

Profa. Alessandra de Sá Mello da Costa Departamento de Administração - PUC-Rio

\begin{abstract}
Prof $^{a}$. Lucia Barbosa de Oliveira Coordenadora da Graduação em Administração Faculdades IBMEC/RJ
\end{abstract}

Prof $^{a}$. Sandra Regina da Rocha Pinto Departamento de Administração - PUC-Rio

Prof $^{\text {a }}$. Mônica Herz

Vice-Decana de Pós-Graduação do CCS

Rio de Janeiro, 8 de abril de 2011 
Todos os direitos reservados. É proibida a reprodução total ou parcial do trabalho sem autorização da universidade, da autora e da orientadora.

\section{Paula Gonçalves Barbosa}

Graduou-se em Administração de Empresas pela PUC-Rio em 2003. Trabalhou na área de Recursos Humanos com Remuneração desde o início de sua carreira profissional, exercendo inicialmente a função de Analista de Recursos Humanos. Atualmente, desde 2009, trabalha como Coordenadora de Planejamento, Programação e Controle de Produção na área de Produção da H.Stern.

\section{Ficha Catalográfica}

\section{Barbosa, Paula Gonçalves}

Profissão de ourives: descobrindo valores e motivações de diferentes gerações de profissionais / Paula Gonçalves Barbosa; orientadora: Ana Heloisa da Costa Lemos. - 2011.

112 f. ; $30 \mathrm{~cm}$

Dissertação (mestrado) - Pontifícia Universidade Católica do Rio de Janeiro, Departamento de Administração, 2011.

Inclui bibliografia

1. Administração - Teses. 2. Valores no trabalho. 3. Gerações. 4. Profissionais de ourivesaria. I. Lemos, Ana Heloisa da Costa. II. Pontifícia Universidade Católica do Rio de Janeiro. Departamento de Administração. III. Título. 
Ao meu pai, Antonio, meu grande herói e inspiração na minha vida.

À minha mãe Irenides, por todo amor, paciência e ensinamentos. À minha irmã, Daniele, pela nossa amizade, apoio e carinho. 


\section{Agradecimentos}

À minha orientadora, Ana Heloisa da Costa Lemos, por todos os ensinamentos, paciência, pronto retornos e por tornar este trabalho realidade.

ÀS minhas irmãs do coração, Adriana Ferreira, Ana Cláudia Louzada e Fernanda Miguel, por estarem sempre ao meu lado, por vibrarem com minhas conquistas e pelas longas conversas.

À H.Stern, especialmente Dr. Ricardo Augusto Barbosa e Looly Oliveira, pela autorização para a realização deste trabalho e ao Antonio Manoel Pais (Tuninho), pelos conselhos e pela parceria que realizamos no dia-a-dia das oficinas de fabricação. 


\section{Resumo}

Barbosa, Paula Gonçalves; Lemos, Ana Heloisa da Costa (Orientadora). Profissão de Ourives: descobrindo valores e motivações de diferentes gerações de profissionais. Rio de Janeiro, 2011. 112p. Dissertação de Mestrado - Departamento de Administração, Pontifícia Universidade Católica do Rio de Janeiro.

A atividade da ourivesaria possui registros desde o Egito antigo e é, tradicionalmente, uma atividade familiar, passada de pai para filho e principal atividade técnica do setor joalheiro. No entanto, esta realidade está mudando e no Brasil existem, atualmente, alguns cursos técnicos para o ensinamento do ofício. Esse movimento decorre, em grande parte, da dificuldade que as empresas enfrentam em recrutar e reter esses profissionais. Diferentemente, do que acontecia em décadas anteriores, quando havia identificação e interesse dos jovens em seguir a profissão de seus pais e avós, atualmente são raros os casos em que a profissão de ourives passa de geração para geração, fazendo com que este profissional seja cada vez mais escasso no mercado. A percepção da dificuldade de atrair e reter esses profissionais motivou a realização dessa dissertação, que buscou identificar os valores desses profissionais, bem como comparar esses valores entre as diferentes gerações que exercem a profissão, atualmente. Para tanto, foi realizada uma pesquisa com um grupo de trinta profissionais do ramo com um questionário fechado e, posteriormente, entrevistas semi-estruturadas, caráter exploratório, com dezesseis profissionais de diferentes gerações e níveis técnicos, visando identificar seus valores e motivações. Uma vez identificados os valores, os mesmos foram classificados e comparados entre as diferentes gerações e analisados à luz da literatura sobre estes assuntos. Com base nos resultados obtidos foram sugeridas ações e políticas capazes de auxiliar na retenção e motivação destes profissionais.

\section{Palavras-chave}

Valores no trabalho; gerações; profissionais de ourivesaria. 


\section{Abstract}

Barbosa, Paula Gonçalves; Lemos, Ana Heloisa da Costa (Advisor). Occupation of Goldsmiths: discovering the values and motivations of different generations of professionals. Rio de Janeiro, 2011. 112p. MSc. Dissertation - Departamento de Administração, Pontifícia Universidade Católica do Rio de Janeiro.

The activity of gold has records since ancient Egypt and is traditionally a family activity, passed from father to son and chief technical activity of the jewelry industry. However, this reality is changing and in Brazil there are currently some technical courses for the teaching of the craft. This movement stems largely from the difficulty that companies face in recruiting and retaining these professionals. Differently than they did in previous decades, when there was interest and identification of young people to follow the profession of their parents and grandparents, now are rare cases in which the profession of goldsmith passes from generation to generation, so that each professional is increasingly scarce in the market. The perception of difficulty in attracting and retaining these professionals led to the realization of this dissertation, which sought to identify the values of these professionals and to compare these values between different generations in the profession today. For this, a search was conducted with a group of thirty industry professionals with a closed questionnaire, and later semistructured, exploratory, with sixteen different generations of professional and technical levels, to identify their values and motivations. Once identified the values, they were classified and compared across generations and analyzed in light of the literature on these subjects. Based on the results was suggested actions and policies that can assist in retention and motivation of these professionals.

\section{Keywords}

Values at work; generations; goldsmiths. 


\section{Sumário}

1. Introdução 12

1.1. Problema de Pesquisa 12

1.2. Objetivos 13

1.3. Questões de Pesquisa 13

1.4. Relevância do Estudo 14

1.5. Delimitações do Estudo 18

1.6. Estrutura da Dissertação 18

2. Referencial Teórico 20

2.1. Valores 20

2.1.1. Conceituando Valores 20

2.2. Valores Relativos ao Trabalho 23

2.3. Gerações 34

2.3.1. Geração Baby Boomers 36

2.3.2. Geração $X$

2.3.3. Geração $Y$

3. Metodologia da Pesquisa 52

3.1. Tipo de Pesquisa $\quad 52$

3.2. Papel do Pesquisador $\quad 52$

3.3. Seleção de Sujeitos $\quad 54$

3.4. Procedimentos de Coleta e Registro de Dados 56

3.5. Limitações do Método 60

4. Análise dos Resultados 61

4.1. A empresa escolhida: H.Stern 61

4.1.1. História da empresa 61

4.1.2. Os Valores da H.Stern 66

4.2. Principais Valores dos profissionais de ourivesaria 66

4.2.1. A Valorização da Estabilidade $\quad 71$

4.2.2. A Importância das Relações Sociais 73

4.2.3. A questão do Prestígio $\quad 77$

4.2.4. A Realização Profissional $\quad 80$

4.2.5. A Valorização do Desafio Profissional 84

4.2.6. A Atualização Profissional 85

4.2.7. O Retorno Financeiro $\quad 89$

4.2.8. A Escolha da Profissão 93

4.2.9. O Aprendizado da Profissão 95

4.2.10. A Percepção de Crescimento na Empresa 98

4.2.11. A Identificação com a Empresa 100

4.2.12. O Sentido do Trabalho 103

5. Conclusões e Recomendações 105

6. Referências bibliográficas 110 


\section{Lista de figuras}

Figura 1: Escolinha de Ourivesaria da H.Stern. 17

Figura 2: Estrutura motivacional dos valores. $\quad 27$

Figura 3: Estrutura bidimensional dos valores. 28

Figura 4: Modelo de valores gerais e de trabalho. 33

Figura 5: Guided Tour - visita guiada às etapas de fabricação. 61

Figura 6: Novos designs para as jóias. 63

Figuras 7 e 8: Jóias para coleções mundiais (esquerda) e jóias com foco nas pedras brasileiras (direita).

Figura 9: Sede da H.Stern em Ipanema. 64

Figuras 10 e 11: Loja de Miami (esquerda) e loja em Ipanema (direita). 64

Figuras 12, 13 e 14: Mudanças na logomarca da H.Stern. 64

Figura 15: Campanhas de Marketing da H.Stern. 65

Figura 16: Celebridades mundiais usam jóias H.Stern em eventos. 65 


\section{Lista de gráficos}

Gráfico 1: Resultados Gerais Valores no Trabalho. 70

Gráfico 2: Valores no Trabalho para Geração Y.

Gráfico 3: Valores no Trabalho para Geração X. 72

Gráfico 4: Valores no Trabalho para Geração Baby Boomers. 72

Gráfico 5: Área de Relações Sociais nos Valores do Trabalho, pergunta

20.

Gráfico 6: Área de Relações Sociais nos Valores do Trabalho, pergunta

23.

Gráfico 7: Área de Prestígio em Valores do Trabalho, pergunta 25.

Gráfico 8: Área de Prestígio em Valores do Trabalho, pergunta 6.

Gráfico 9: Área de Realização no Trabalho em Valores do Trabalho, pergunta 4.

Gráfico 10: Área de Realização no Trabalho em Valores do Trabalho, pergunta 10.

Gráfico 11: Área de Prestígio em Valores do Trabalho, pergunta 35.

Gráfico 12: Área de Realização no Trabalho em Valores do Trabalho, pergunta $38 . \quad 89$

Gráfico 13: Área de Estabilidade nos Valores do Trabalho, pergunta 9.92

Gráfico 14: Área de Estabilidade nos Valores do Trabalho, pergunta 40. 92

Gráfico 15: Área de Prestígio em Valores do Trabalho, pergunta 15.99 


\section{Lista de quadros}

Quadro 1: Fatores da Escala de Valores Relativos ao Trabalho. 31

Quadro 2: População de ourives, modelistas e auxiliares da H.Stern. 55

Quadro 3: Perfil dos Entrevistados. 56

Quadro 4: Questionário de valores no trabalho. 57

Quadro 5: Roteiro de entrevista. $\quad 59$

Quadro 6: Categorias de Valores. $\quad 67$

Quadro 7: Perfil dos Entrevistados. Fonte: Elaborado pela autora. 68

Quadro 8: Gerações e cargos de profissionais. 68

Quadro 9: Características das gerações. 70 